\title{
Foundation Types for Land and Offshore Sustainable Wind Energy Turbine Towers
}

\author{
C Lavanya ${ }^{1}$ and Nandyala Darga Kumar $^{2}$ \\ ${ }^{1}$ Professor, Department of Civil Engineering, GRIET, Hyderabad, Telangana, India \\ ${ }^{2}$ Assistant Professor, Department of Civil Engineering, JNTUHCE Manthani, Peddapalli, Telangana, India
}

\begin{abstract}
Wind energy is the renewable sources of energy and it is used to generate electricity. The wind farms can be constructed on land and offshore where higher wind speeds are prevailing. Most offshore wind farms employ fixed-foundation wind turbines in relatively shallow water. In deep waters floating wind turbines have gained popularity and are recent development. This paper discusses the various types of foundations which are in practice for use in wind turbine towers installed on land and offshore. The applicability of foundations based on depth of seabed and distance of wind farm from the shore are discussed. Also, discussed the improvement methods of weak or soft soils for the foundations of wind turbine towers.
\end{abstract}

\section{Introduction}

In the recent years the renewable and sustainable energy sources have gained popularity due to increased oil prices, emission of carbon dioxide and over exploitation of fossil fuels. Wind based energy is the one; it can be generated at low cost [1]. Wind power can be generated from onshore and offshore. In the Europe there are good numbers of offshore windmill projects in operation and $90 \%$ of total power is generated from these projects [2].

Wind turbines are commonly used to produce wind based electric energy. Turbines use a rotating motion to generate electricity. Stability of wind turbine is very important and is ensured by providing an appropriate foundation. The main task of foundation of wind turbine is that it transfers and spreads the loads to the soil at depth. The vertical and horizontal forces which act on the turbine foundation are due to self-weight and wind respectively. The height of wind turbine tower varies usually from $40 \mathrm{~m}$ to $130 \mathrm{~m}$. Wind speed increases as the height of wind turbine tower increases. The wind force acting on the turbine generates a large moment at the foundation base level [3].

The design of any structure aims to ascertain its component sizes and type of foundation that are suitable and safe for the filed loading and environmental conditions. The probability of failure of any structure depends on the material strength and the loading that are considered in the design. Along with partial safety factors of material strength, the geotechnical foundations and soil conditions are also very important in arriving safe design and stability of the structure to stand for long life.

\section{Foundation Types for On Land Wind Turbine Towers}

Many sustainable foundation types and methods are available for wind turbines of on land. The foundation for on land wind turbine towers can be grouped into two types: (i) spread foundations and (ii) piled foundations. In both the foundation types, an interface which is embedded in foundation concrete must be provided between the turbine tower and foundation to ensure the connectivity and stability. Some instances, the interface decides the type of foundation to be provided for wind turbine tower.

\subsection{Spread foundation}

A spread foundation spreads the loads coming from the wind turbine tower to the soil. It is like a slab foundation and consists of a large plate that provides large area for spreading the loads to the soil. In majority times, the shape adopted in the spread footing is cylindrical or a square prism. The construction materials used to construct a spread footing are reinforced concrete. 
As the base area of spread footing is larger, the pressure acting on the soil would be smaller. This decreased pressure on the soil due to large base area ensures that it will not exceed the maximum allowable soil pressure. Also, there is an advantage of spread footing that it resists the overturning moments caused due to wind and eccentric dead loads. Settlement of a structure is nothing but, its vertical downward movement and it depends on the loading and soil conditions. The spread footings help maintaining differential settlements low.

Where strong and stiff soils are encountered, the spread footing can be considered as more sustainable foundation method wherein settlements are small. The spread footings are not common in clays, silty clays, unconsolidated fillings and organic soils which have low modulus of elasticity.

Due to soil pressure at the bottom of the footing, there acts shear force. The reinforcement stirrups must be put in for the footings of insufficient thickness so that the shear failure can be very much controlled. The interface between tower and foundation consists of a "ring" or "boltcage". It is necessary to analyze the forces that arise in the interface in the form of tension and compression due to overturning effects. It needs to be provided with extra reinforcement at the interface level to prevent the associated damage.

\subsubsection{Shallow foundation}

Shallow foundation is one of the groups of spread footing. When a spread foundation is placed on the ground, or just beneath it, is termed as shallow foundation (Fig.1). The base area of the shallow foundation is large enough to prevent the overturning of the wind turbine tower. The constriction of the shallow foundation is done in a way that the resultant of all the forces should be close to the center of the footing at the base level. This can be achieved by providing a thick heavy construction. This type of foundation is sustainable because it is quite easy to build; little excavation and refilling work is needed.

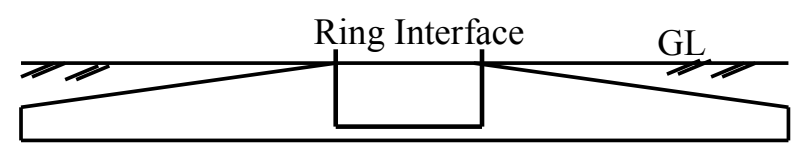

In-situ soil

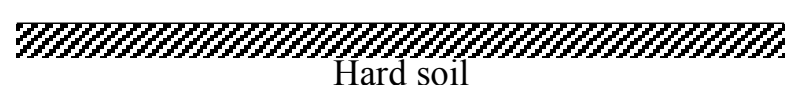

Fig. 1. Spread foundation on the ground

\subsubsection{Gravity Foundation}

Gravity foundation is one of the spread foundation types and is placed some depth below the ground surface by excavating the soil. After construction of it, the excavated portion is refilled either with same soil or good soil (Fig.2). For better sustainability of wind turbine tower, it is always suggested to place the gravity foundation on strong soil layer instead of weak/or soft soils. Due to embedment of gravity footing into soil certain depth, the weight of the filling soil placed above the footing base will enhance the stability that the structure doesn't undergo overturning. It provides sustainability in terms of reduced overturning and amount of concrete required for the gravity footing. The only drawback of this type of foundation is that it requires excavation and refilling activities.

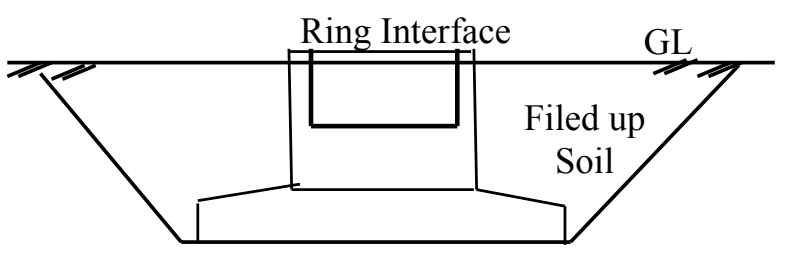

In-situ soil

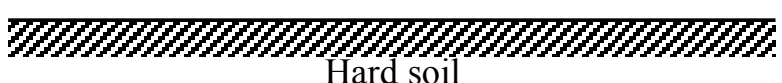

Fig. 2. Gravity type foundation

\subsection{Pile Foundations}

It is known that the soil properties are not the same at every construction location. The soil properties vary based on the local geology and the weathering type which the rocks would undergo. The soil type decides whether to opt spread footing or pile foundation for the wind turbine tower. Especially, where huge loads are required to be transferred on to the soil and if foundation soil is weak/or soft, most of the designers recommend going for pile foundations which are very much sustainable to support the structure from overturning and other settlement associated problems. The pile foundations can sustain the tensional effects due to wind imposed bending moments on the structure.

The connection between the piles and the plate is important for the load distribution. Piles are connected to the plate by two means of (i) clamped connection and (ii) hinged connection. In the clamped case, the pile top will experience a large bending moment and in the hinged case, the pile top will not experience it. Pile group foundation consists of a steel plate or concrete plate, which serves as a connection between the group of piles and the wind turbine tower. The plate width should be decided in such a way that the piles should not 
experience tension loads. And sometimes piles can be driven to deeper depths to avoid the failures associated with tension loads.

\subsubsection{Placement of Piles on Bedrock}

Based on the geological formations sometimes, the bed rock can be identified at reasonable shallow depth. In such situations, for better sustainability point of view of wind turbine tower, the piles can be driven or placed at such bedrock formation levels. It will ensure the minimum settlement because, the settlement that mostly going to occur is due to pile deformations, not by soil compression at pile tip level. In this case, it is assumed that the soil is not going to share any load.

Sometimes if necessary, piles can be anchored into the bedrock so that they can sustain comfortably the tension loads, which are mostly due to the wind actions on the wind turbine tower. In such situations estimation of load carrying capacity of anchored piles is a challenging one for the designers and it needs experience in understanding the geotechnical and rock parameters and knowledge on pullout tests.

\subsubsection{Piled Raft Foundation}

The combination of spread foundation and group of piles is termed as piled raft foundation. The spreading of load in the top portion of soil is achieved with the help of spread foundation and the group of piles in the foundation will transfer the huge loads to the deeper depths. To ensure the load carrying capacity of both spread foundation and group of piles, it is required to see that there should not be any gap left between them and these foundations are surrounded with the soil effectively. Generally, piles are not effective in the cases of firm soil and bedrock because, gaps are left between piles and soil/rock, and this will result in reduced shaft friction load. The number of piles required, and their depth of termination are decided based on the equal settlement concept and pile group capacity. The design of piled raft preferably carried out using finite element method-based software. The stiffness of raft and pile are important while modeling the piled raft analysis.

\section{Types of Foundations for Offshore Wind Turbine Towers}

The depth of sea is classified as shallow waters ( 0 $30 \mathrm{~m})$, transitional waters $(30-50 \mathrm{~m})$, and deep waters $(50-200 \mathrm{~m})$ [4]. The cost of foundation for offshore wind farms increases significantly as the depth of sea increases from shallow waters to deep waters. Based on the construction location of wind farm in the offshore regions, a suitable foundation type is required to choose for wind turbine tower in order to achieve sustainability. In shallow waters, gravity type and monopile type foundations are used commonly.

Monopile type foundation is used most commonly rather than the gravity type foundation. Gravity type foundation is expensive to construct in sea depths beyond $10 \mathrm{~m}$. In sea depths more than $10 \mathrm{~m}$, a monopile type foundation and a multipod type foundation are commonly constructed. Multipod includes both tripod and jacket combination. Multipod type foundations are generally preferred in sea depths beyond $30 \mathrm{~m}$ in order to minimize the foundation cost. The selection of type of foundation for offshore wind turbine tower is governed by the sea depth, distance from shore and the capacity of wind turbine. High economic feasibility and sustainability can be achieved, if multipod type foundation is deployed in deep seas region, which is located very far from shore. The different sustainable foundation types which are in practice for offshore wind farms are discussed in the following sub sections.

\subsection{Gravity}

A gravity-type foundation derives stability from its self-weight and is the first kind of foundations used in offshore wind farms. It consists of a large circular pile with a concrete plate structure resting on the seabed especially in shallow waters close to shore (Fig.3). Initially, in most wind farm projects in offshore, the gravity type of foundation was used, because of the availability of mature construction expertise and installation technology that can minimize the risk [5].

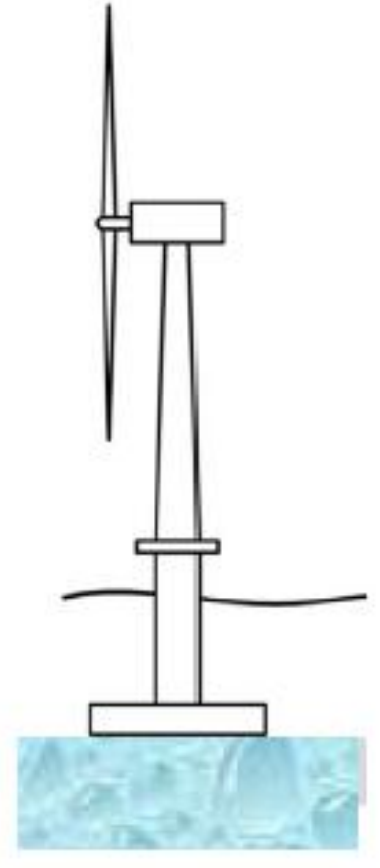

Fig. 3. Gravity type foundation

\subsection{Monopile}


Monopile type foundations (Fig.4) have gained lot of popularity in the recent past especially in European offshore wind farms. The reasons for high use of monopile type foundations in the North Sea, Europe are: (i) installation in shallow waters where sea depth is less than $30 \mathrm{~m}$, (ii) the soil available at the farm sites is sand and gravel, which needs no effort to drive the piles.

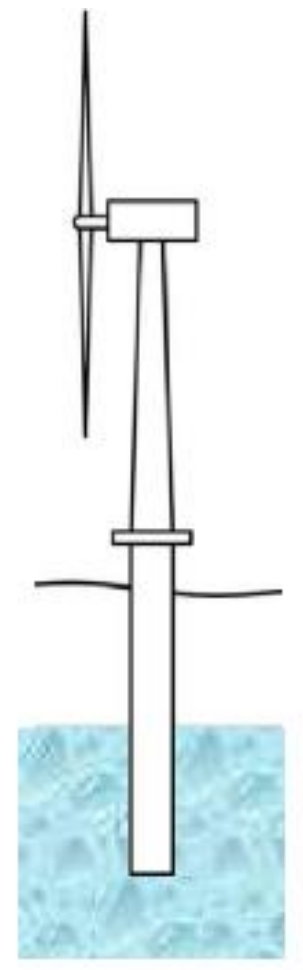

Fig. 4. Monopile foundation

This monopile type foundation technology is the most economical one for water depths less than $30 \mathrm{~m}$ and for seabed of sand and gravel type [6]. Monopile type foundations can reduce the maintenance cost of materials [7]. Installation of monopole for wind farms in the offshore regions require jack-up barges, which cause considerable vibration, noise, and develops suspended sediment. The marine ecosystem at the installation site can be disturbed.

\subsection{Suction Caisson}

A suction caisson type foundation is an ecofriendly foundation because; it does not require any heavy equipment for piling or installation. It looks like an upside-down bucket (Fig. 5). Installation of this type of foundation does not produce high level vibration, noise and suspended sediment. It is an economical foundation technique, because it can be installed very quickly with simple procedure [6].

Suction caisson can reduce the steel weight by 50 per cent as compared with a monopile [8]. The construction cost of tripod suction caisson foundation is half of the construction cost of foundation made with jacket piles for the same seabed geology [9]. As per the construction and installation perspectives are concerned the suction caissons can be considered as an excellent foundation choice for the offshore wind farms.

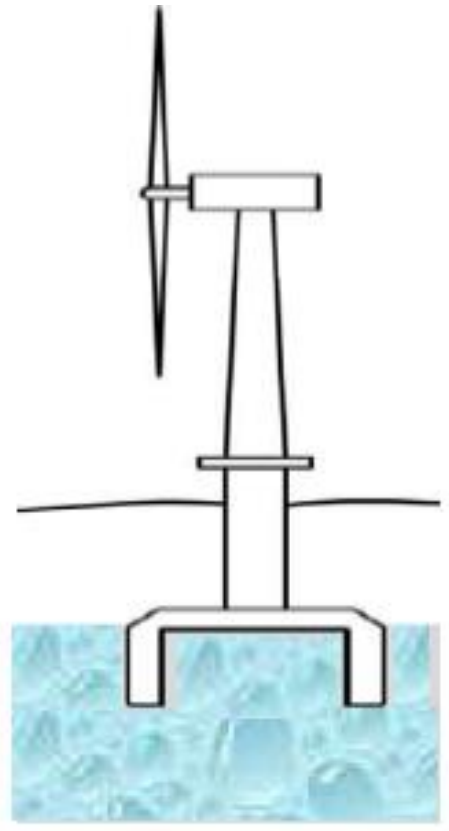

Fig. 5. Suction caisson foundation

\subsection{Multipod (Tripod and Jacket)}

Space frame substructures such as tripod and jacket structures can provide the required strength and stiffness (Fig.6). Tripod and jacket structures are effective in transitional water depths with relative short penetration length. These types of foundations reduce the construction costs when installed in transitional water depth. The weights of tripods and jackets used in multipod are low and hence it is an economical foundation [6]. Multipod can be more effective than monopile. In the extreme events of hurricanes and typhoons, the multipod type of foundation is most preferred than monopile and suction caisson, because these foundations need larger embedment depth and size.

\subsection{Floating Substructures}

These types of foundations are still in development stage and are classified into three categories namely: (i) Ballast stabilized, (ii). Mooring line stabilized and (iii) Buoyancy stabilized foundations. Floating structures have many advantages in deep waters in cost, construction and installation [10].

Ballast stabilized foundations are reliable and economical [11]. Floating units are arranged with a certain geometrical pattern by using cables. A stabilized barge is mainly used for the buoyancy 
stabilized foundation. The stabilized barge is connected to the seabed by using anchors [12].

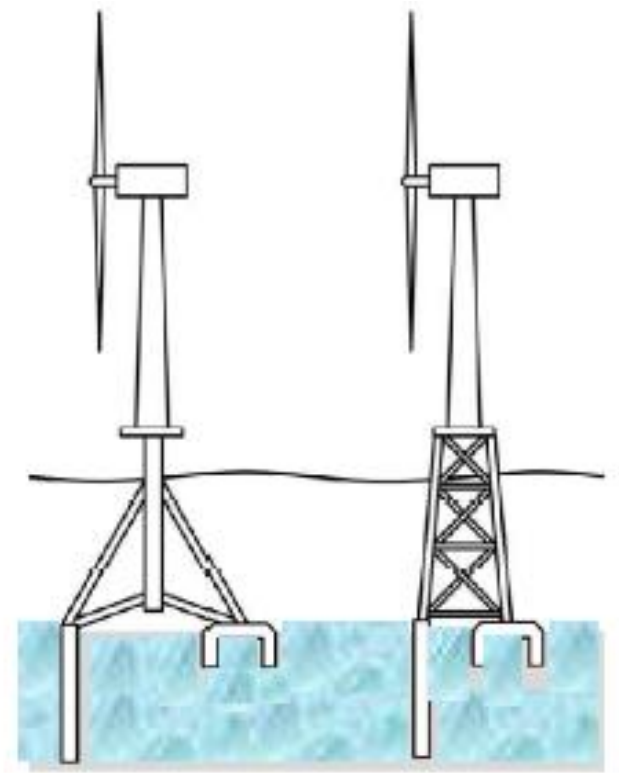

Fig. 6. Multipod foundation (Tripod and Jacket type)

\section{Stabilization of Soil for Wind Turbine Tower Foundations}

Heavy weight wind farms transmit huge loads on to the soil through the foundation. To sustain such huge loads, the soil should have enough bearing capacity. Generally weak/soft soils will have low bearing capacity and these sites are straightaway cannot be used for building the foundations for wind farms. Hence, soil properties such as soil stiffness, shear strength and permeability are required to be improved. There are many different methods for doing this. The most common methods that are followed to improve the site conditions are compaction/densification methods and methods of soil reinforcement.

The settlements of soil can be minimized by exposing the soil to preloading and/or compaction. Also, vibratory methods can be employed to control the settlement of soil. By dynamic consolidation process, dropping of heavy weights on the ground or by depth vibration with vibrating machines, the in-situ soil can be dandified.

By using additional materials, the in-situ soil can be reinforced or strengthened. Permeation grouting method is the one such method, in which the grout material is sent with force in order to occupy or fill the voids in the ground. This permeation grouting method reduces the permeability and hence controls the settlement and increases the strength of soil. Jet grouting method is another similar method, which uses column-like structures made of soil-grout mixture. These jet grout columns are produced from the designed depth to the ground surface by rotating the drill rod at a controlled rate and at the same time a jet of grout filling the spaces between the soil particles. These elements are not really columns but columns-like soil improvements.

Deep soil mixing is another method used to improve the soil. A machine equipped with a mixing tool is driven down in the soil rotating. The mixing tool is then slowly retracted, still rotating and at the same time lime and cement is blown into the soil mixing with the soil. The lime reacts with the water in the undrained soil forming a new product with lower water content, much higher stiffness and stronger. This might be a suitable method if the soil quality is not good and the distance to the bedrock is at too great depth. If poor soil is involved within the shallow depth, then this soil can be replaced with better soil and compacted to achieve the desired geotechnical properties of soil.

\section{Conclusions}

From the discussion on various types of foundations for on land and offshore wind farms, it is clear that gravity type foundations can sustain from the loads effectively and are most applicable especially in shallow waters and on land. Suction caisson foundations are cost effective solutions in deep water wind farms and they can be easily installed. The tripod or jack up multipod systems are 50 per cent less cost than the monopole foundation for locations of similar geology. In the recent times floating wind turbine concept is developed for deep water wind farms.

\section{References}

1. Global wind report annual market update, Available from http://www.gwec.net/wpcontent/uploads/2015/ 03/GWEC_Global_Wind_2014_Report_LR.p df (2014)

2. Achmus M, Wörden FT. Geotechnical aspects of the design of foundation structures for offshore wind energy converters. Bauingenieur, 43, 157-65 (2013)

3. World Wind Energy Association (WWEA), The Structure of a Modern Wind Turbine - An Overview, Webpage: http://www.wwindea.org/technology/ch01/estr uctura-en.htm.

4. Musial W, Butterfield S. Future for offshore wind energy in the United States. NREL, CP500-36313, (2004)

5. Mengé $P$, Gunst N. Gravity Based Foundations for the Wind Turbines on Thorntonback- 
Belgium. 15deInnovatie forum Geotechniek, Antwerpen, Belgium (2008)

6. Review of Options for Offshore Foundation Substructures Prepared by the Center for Wind Energy at James Madison University (2012)

7. Oh K-O, Kim J-Y, Lee J-S. Preliminary evaluation of monopile foundation dimensions for an offshore wind turbine by analyzing hydrodynamic load in the frequency domain. Renew Energy, 54 :211 (2013)

8. Ibsen LB, Liingaard M, Nielsen SA. Bucket Foundation, a status. Copenhagen, Denmark: Copenhagen offshore wind (2005)

9. Ryu MS, Kim J-Y, Lee J-S. Comparison of two meteorological tower foundations for offshore wind turbines. In: Proceedings of the twenty-sixth international offshore and polar engineering conference. Rhodes, Greece, (2016)

10. Jonkman JM, Buhl JrML. Loads analysis of a floating offshore wind turbine using fully coupled simulation. In: Proceedings of the wind power 2007 conference and exhibition. Los Angeles, USA (2007)

11. Skaare B, Hanson TD, Nielsen FG. Importance of control strategies on fatigue life of floating wind turbines. In: Proceedings of the 26th International conference on offshore mechanics and arctic engineering. San Diego, USA, (2007)

12. Wayman EN, Sclavounos PD, Butterfield S, Jonkman J, Musial W. Coupled dynamic modeling of floating wind turbine systems. In: Proceedings of the offshore technology conference, Texas, USA (2006). 